\title{
Acute hemoptysis due to incarcerated intercostal hernia after uniportal lobectomy: case report
}

\author{
Gustavo E. Guajardo-Salinas^ \\ Thoracic Surgery, Texas Oncology San Antonio, San Antonio, TX, USA \\ Correspondence to: Gustavo E. Guajardo-Salinas, MD. Thoracic Surgery, Texas Oncology San Antonio, 18707 Hardy Oak Blvd, Suite 320, San \\ Antonio, TX 78258, USA. Email: Gustavo.guajardo-salinas@usoncology.com.
}

\begin{abstract}
Intercostal lung hernia after uniportal thoracoscopic lobectomy is an uncommon condition and only a few cases have been reported. We report a unique case of 76 y/o male that presented with acute hemoptysis and subcutaneous emphysema after a uniportal right upper lobectomy due to intercostal lung hernia. The patient was found to have an acute incarcerated lung hernia in the immediate post-operative period that required an urgent operation to reduce and repair the hernia. The patient had bronchial asthma and significant postoperative cough which likely predisposed him to acute lung herniation. There are very few case reports in the literature of intercostal hernia after uniportal or multi-portal thoracoscopic lobectomy but none with significant hemoptysis requiring urgent surgery. Significant hemoptysis in patients after lobectomy is very unusual. Bronchovascular fistulas and lung ischemia are common etiologies of post-operative hemoptysis in thoracic surgery. Chest computed tomography (CT) with angiography and bronchoscopy are the tools of choice to promptly make the diagnosis. In our case, the incarcerated intercostal hernia caused a haematopneumatocele and this resulted in hemoptysis. The presentation of chest wall pain, subcutaneous emphysema and hemoptysis in the postoperative period after thoracoscopic lobectomy is highly suggestive of acute incarcerated intercostal hernia. Patients with acute hemoptysis after lobectomy should undergo CT chest angiography to rule out incarcerated intercostal hernia. Post-operative cough can be a risk factor for developing acute intercostal hernias.
\end{abstract}

Keywords: Hemoptysis; uniportal; intercostal lung hernia; case report

Received: 01 March 2021; Accepted: 24 March 2021; Published: 30 June 2021.

doi: $10.21037 /$ asj-21-5

View this article at: http://dx.doi.org/10.21037/asj-21-5

\section{Introduction}

Intercostal lung hernias are rare after thoracic surgery. The incidence of post lobectomy lung hernias after thoracoscopic surgery is very rare. Most hernias are found incidentally in follow-up computed tomography (CT) scans and the majority are asymptomatic. Very few cases have been reported in the literature after video-assisted thoracoscopic surgery (VATS) for the lungs; to date there has been 11 cases to our knowledge (1). The majority of the reported cases had a right upper lobectomy (2). To our knowledge, there are no cases reported in patients with a history of uniportal thoracoscopic lobectomy with acute presentation and frank hemoptysis (3). Most patients with intercostal lung hernias present with pain at the site or bulge in chest wall. In some instances, the presentation of intercostal hernias can be with acute incarceration with subcutaneous emphysema and increase in pain at the incision site. Frank hemoptysis is a rare presentation for intercostal hernias, only in one previously reported case after thoracoscopic lobectomy, the patient presented with hemosputum (1-3).

In one the largest series of intercostal hernias after

\footnotetext{
^ ORCID: 0000-0002-3870-8915.
} 


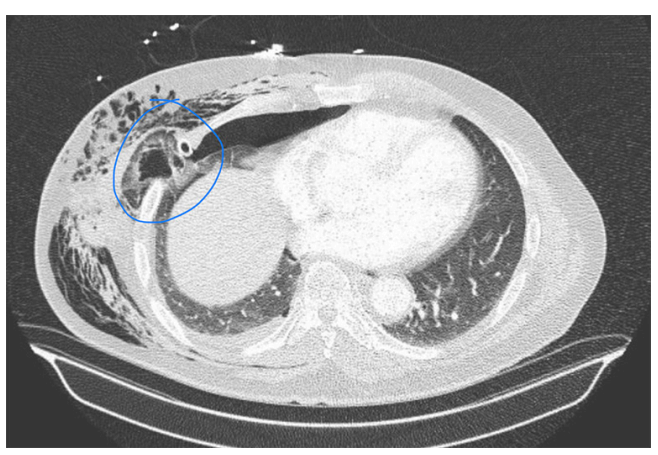

Figure 1 CT chest demonstrating intercostal hernia (blue circle) with lung tissue incarcerated and subcutaneous emphysema.

thoracoscopic lobectomy, the presentation of all the cases described was several months after the procedure and none of the patients had hemoptysis. We report a unique case of acutely incarcerated lung hernia after uniportal right upper lobectomy that presented with hemoptysis and subcutaneous emphysema in the immediate post-operative period. Acute hemoptysis caused by an acutely incarcerated intercostal hernia after uniportal lobectomy is a very rare presentation (1-3).

The diagnosis of intercostal hernias is suspected by clinical exam when a patient complaints of a bulge in the chest wall during cough and pain at the site (1). In some patients, subcutaneous emphysema is also present, particularly if they are incarcerated. The gold standard to diagnose an intercostal hernia has been CT scan of the chest, as it clearly defines the anatomy and identifies the lung parenchyma herniating through the intercostal space (4). I present the following article in accordance with the CARE reporting checklist (available at https://asj. amegroups.com/article/view/10.21037/asj-21-5/rc).

\section{Case presentation}

A 76 y/o male with history of gastric gastrointestinal stromal tumor that was resected in 2016 and subsequently was treated with imatinib for 1 year. He presented for yearly follow-up and was found to have a right upper lobe mass of $2.9 \mathrm{~cm}$ on computed tomography of the chest. He then underwent a percutaneous CT guided biopsy and pathology demonstrated adenocarcinoma of the lung. He had no history of smoking and his only other known medical problem was hypertension and bronchial asthma. He underwent preoperative evaluation with transthoracic echocardiogram (TTE) and pulmonary function tests.
His TTE demonstrated moderate to severe mitral valve regurgitation with normal ejection fraction $(65 \%)$ but he was asymptomatic with no activity limitation and required no intervention at the time. His pulmonary function tests demonstrated FEV1 of 2.8 liters and DLCO of $81 \%$ with mild obstructive disease with response to bronchodilators suggestive of bronchial asthma. Positron emission tomography demonstrated no signs of mediastinal lymphadenopathy or metastatic disease. He was offered surgical resection after being evaluated by cardiology. $\mathrm{He}$ underwent uniportal thoracoscopic right upper lobectomy with mediastinal lymph node dissection using a $4.5 \mathrm{~cm}$ incision in the $5^{\text {th }}$ intercostal space. Initially his postoperative course was uncomplicated with a very small expiratory air leak, minimal pain and occasional cough. On postoperative day 2 his cough worsened and he complaint of increased right chest wall pain. He also had a small amount of hemoptysis (approx 5-10 cc) during a cough spell. He was treated with antitussives, bronchodilators, empiric antibiotics and steroids with the presumptive diagnosis of acute bronchitis and pneumonia. His cough improved as well as his pain and his chest X-ray demonstrated small apical pneumothorax and mild subcutaneous emphysema. On post-operative day 4 his subcutaneous emphysema acutely worsened as well as his cough and he had a second episode of hemoptysis but this time approximately $20 \mathrm{~mL}$ of bright red blood. He remained stable, with minimal oxygen requirements but his subcutaneous emphysema did not correlate to his small air-leak on his chest tube and worsened despite using suction $-20 \mathrm{~cm}$ of $\mathrm{H}_{2} \mathrm{O}$. A CT angiogram was performed and demonstrated an intercostal hernia with trapped lung and no obvious site or explanation of his hemoptysis (Figure 1). He was taken to the operating room for re operative uniportal VATS. Upon opening his incision a purplish mass was seen in the subcutaneous tissue consistent with incarcerated necrotic lung tissue (Figure 2). The lung tissue was pushed into the chest cavity and the camera inserted. A portion of the right lower lobe had become trapped and incarcerated in the wound and became necrotic. A simple wedge resection of the lung tissue was performed (Video 1). The specimen was opened in the operating room table finding a pneumatocele filled with blood inside (Figure 3), explaining the hemoptysis and the subcutaneous emphysema. The intercostal space was closed with 3 intercostal sutures and the patient had an uneventful recovery afterwards.

Pathology report from his lobectomy demonstrated Invasive Adenocarcinoma T2a N0 Stage (22 negative lymph 


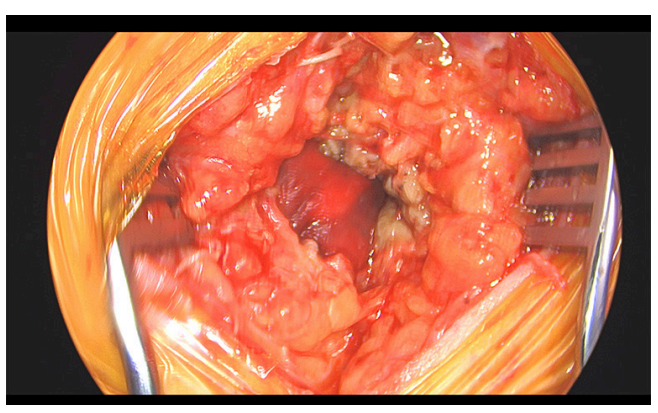

Figure 2 Intra operative picture of incarcerated lung after opening the surgical incision.

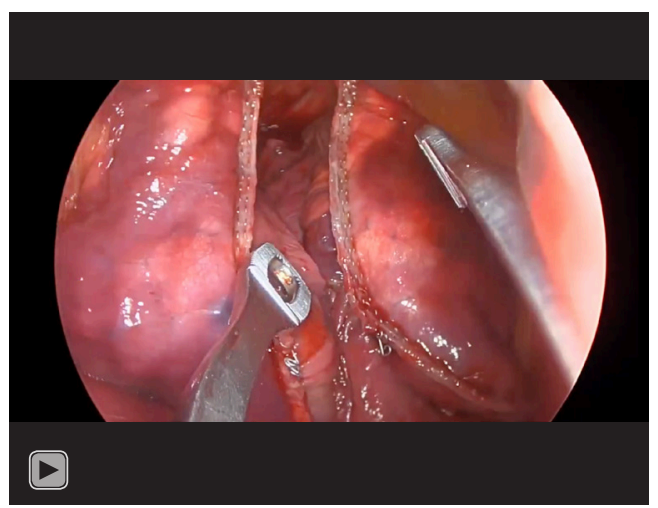

Video 1 Video demonstrating the VATS wedge resection of lung tissue containing the haematopneumatocele. VATS, video-assisted thoracoscopic surgery.

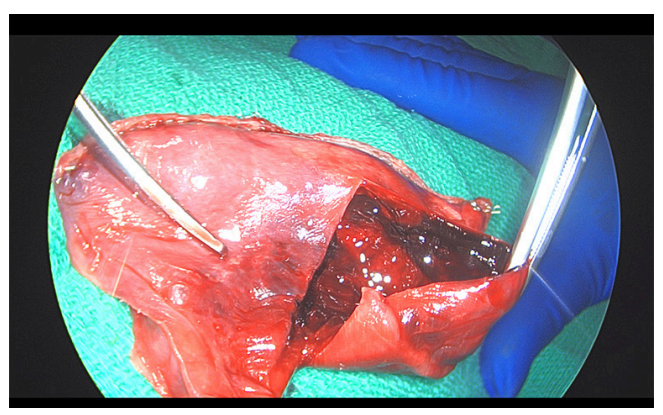

Figure 3 Wedge of right lower lobe demonstrating haematopneumatocele.

nodes) Stage IB. His wedge resection demonstrated intraparenchymal hemorrhage and organizing pneumonia. Follow-up imaging demonstrated only post lobectomy changes and no evidence of recurrence of hernia.

All procedures performed this study were in accordance with the ethical standards of the institutional and/or national research committee(s) and with the Helsinki Declaration (as revised in 2013). Written informed consent was obtained from the patient for publication of this case report and accompanying images. A copy of the written consent is available for review by the editorial office of this journal.

\section{Discussion}

Acute lung hernia and hemoptysis after a lobectomy is a very rare finding, specially in the acute postoperative period. The triad of acute hemoptysis, increased subcutaneous emphysema without significant air leak and cough should be considered all highly suggestive of acute incarcerated intercostal lung hernia. The occurrence of intercostal hernia after VATS or uniportal thoracoscopic surgery is extremely rare (1-3). The largest series reported in the literature has 3 cases only and to date only 8 cases have been reported individually to our knowledge (1). The acute presentation only 4 days after surgery like in our case and the presence of hemoptysis is very rare and we attributed this to the patient cough spells likely from untreated bronchial asthma. We reviewed the literature and could only found one case of hemosputum after VATS lobectomy due to intercostal hernia (2).

Intercostal hernias are usually postoperative at the site of previous access incision but have also been described on patients with acute severe episodes of cough and no previous thoracic surgeries. There are not enough cases in the literature to determine weather intercostal hernias are more common with uniportal VATS compared to multiportal VATS lobectomies, but it is unlikely that there is a difference in the incidence since most hernias present at the utility incision site $(3,4)$. Curiously, most hernias described after thoracoscopic lobectomies had a right upper lobectomy, which is considered a risk factor (2,5-8). Lung hernias can also occur after open thoracic operations and lobectomies, in some series intercostal hernias have been associated with minimally invasive surgery, where the intercostal incision is longer than the skin incision $(9,10)$. The cause of hemoptysis in our case was a pneumatocele formed in the right lower lobe that was incarcerated and we hypothesize that it was caused by repeated trauma between the ribs due to the cough of the patient.

Hemoptysis in patients after lobectomy is very rare and in patients that are not at risk of bronchovascular fistulas like patients with history of sleeve lobectomies the 
differential diagnosis is lung ischemia (from incarcerated lung or devascularized lung parenchyma) and/or airway trauma. CT angiogram of the chest and bronchoscopy are important tools to make a prompt diagnosis like in our case $(3,4)$. The treatment for acute incarceration with symptoms is surgical correction, this can be accomplished by closure of the space with intercostal sutures or using mesh to repair the defect $(1,2,5-8)$. We believe our case contributes to the literature to expand the knowledge of potential complications after thoracoscopic surgery and differential diagnosis of post-operative hemoptysis. For patients that present with increase pain at the incision site, subcutaneous emphysema and cough, the clinician should highly suspect an intercostal hernia. Patients with acute hemoptysis after thoracoscopic lobectomy should undergo CT scan of the chest to rule out incarcerated intercostal hernia.

\section{Acknowledgments}

Funding: None.

\section{Footnote}

Reporting Checklist: The author has completed the CARE reporting checklist. Available at https://asj.amegroups.com/ article/view/10.21037/asj-21-5/rc

Conflicts of Interest: The author has completed the ICMJE uniform disclosure form (available at https://asj.amegroups. com/article/view/10.21037/asj-21-5/coif). The author has no conflicts of interest to declare.

Ethical Statement: The author is accountable for all aspects of the work in ensuring that questions related to the accuracy or integrity of any part of the work are appropriately investigated and resolved. All procedures performed in this study were in accordance with the ethical standards of the institutional and/or national research committee(s) and with the Helsinki Declaration (as revised in 2013). Written informed consent was obtained from the patient for publication of this case report and accompanying images. A copy of the written consent is available for review by the editorial office of this journal.

Open Access Statement: This is an Open Access article distributed in accordance with the Creative Commons Attribution-NonCommercial-NoDerivs 4.0 International License (CC BY-NC-ND 4.0), which permits the non- commercial replication and distribution of the article with the strict proviso that no changes or edits are made and the original work is properly cited (including links to both the formal publication through the relevant DOI and the license). See: https://creativecommons.org/licenses/by-nc-nd/4.0/.

\section{References}

1. Bathan G, Yaldız D, Ceylan KC. A rare complication of video-assisted thoracoscopic surgery: lung herniation retrospective case series of three patients and review of the literature. Wideochir Inne Tech Maloinwazyjne 2020;15:215-9.

2. Haneda H, Okuda K, Nakanishi R. Case of intercostal lung hernia with hemosputum that developed after thoracoscopic lobectomy. Asian J Endosc Surg 2019;12:449-51.

3. Kouritas VK, George RS, Brunelli A, et al. Lung herniation after uniportal video-assisted thoracic surgery lobectomy presenting with subcutaneous surgical emphysema. Eur J Cardiothorac Surg 2016;49:1288.

4. Ishibashi $\mathrm{H}$, Hirose $\mathrm{M}$, Ohta S. Lung hernia after videoassisted thoracoscopic lobectomy clearly visualized by three-dimensional computed tomography. Eur J Cardiothorac Surg 2007;31:938.

5. Shomura S, Suzuki H, Yada M, et al. Emergency Surgery for Intercostal Lung Hernia after Right Upper Lobe Resection for Lung Cancer;Report of a Case. Kyobu Geka 2017;70:155-8.

6. Temes RT, Talbot WA, Green DP, et al. Herniation of the lung after video-assisted thoracic surgery. Ann Thorac Surg 2001;72:606-7.

7. Johnson C, Weksler B. Lung hernia after video-assisted thoracoscopic lobectomy. Innovations (Phila) 2010;5:300-2.

8. Kawaguchi T, Yasukawa $\mathrm{M}$, Kawai $\mathrm{N}$ et al. Intercostal Lung Hernia after Video-assisted Thoracoscopic Lobectomy. Kyobu Geka 2016;69:388-91.

9. Subotic D, Wiese M, Hojski A, et al. Surgical Repair of the Postoperative Lung Hernia by Combining Mesh Interposition and Chest Wall Stabilization by Using Synthes Plates: A Novel Technique. Case Rep Surg 2019;2019:2107083.

10. Weissberg D, Refaely Y. Hernia of the lung. Ann Thorac doi: 10.21037/asj-21-5

Cite this article as: Guajardo-Salinas GE. Acute hemoptysis due to incarcerated intercostal hernia after uniportal lobectomy: case report. AME Surg J 2021;1:6. 